\title{
Asthma Endotyping and Biomarkers in Childhood Asthma
}

\author{
Amelia Licari, MD, Riccardo Castagnoli, MD, Ilaria Brambilla, MD, Alessia Marseglia, PhD, \\ Maria Angela Tosca, MD, ${ }^{2}$ Gian Luigi Marseglia, MD, ${ }^{1}$ and Giorgio Ciprandi, MD ${ }^{3}$
}

Childhood asthma represents a heterogeneous challenging disease, in particular in its severe forms. The identification of different asthma phenotypes has stimulated research in underlying molecular mechanisms, such as the endotypes, and paved the way to the search for related specific biomarkers, which may guide diagnosis, management, and predict response to treatment. A limited number of biomarkers are currently available in clinical practice in the pediatric population, mostly reflecting type 2-high airway inflammation. The identification of biomarkers of childhood asthma is an active area of research that holds a potential great clinical utility and may represent a step forward toward tailored management and therapy: the so-called Precision Medicine. The aim of the present review is to provide an updated overview of asthma endotyping, mostly focusing on novel noninvasive biomarkers in childhood asthma.

Keywords: asthma, children, biomarkers, airway inflammation, eosinophils, exhaled nitric oxide, IgE

\section{Introduction}

$\mathrm{C}$ HILDHOOD ASTHMA IS A common chronic airway disease characterized by airway inflammation, airway hyperresponsiveness (AHR), and reversible airway obstruction, affecting around $15 \%$ of school-aged children in Europe, with increasing incidence and prevalence. ${ }^{1,2}$ Symptoms include wheezing, shortness of breath, chest tightness, and cough, ranging in severity from mild symptoms to life-threatening exacerbations. The primary goal of asthma management and treatment is to achieve the control of symptoms and underlying airway inflammation, aiming at minimizing the risk of future exacerbations and medication-related side effects, and preventing the progression of obstructive lung damage during growth and then later in life. ${ }^{1}$ While the majority of asthmatic children have mild or moderate disease and can be adequately controlled with standard medications, a minority (around 5\%) of children with asthma suffer from a severe uncontrolled disease, carrying a significant health and socioeconomic burden, and requiring additional but still limited therapeutic options. ${ }^{3}$

The recognition of different disease variants (phenotypes), even in childhood, has recently allowed to overcome the so far rooted and simplified view of asthma as a single disease., Childhood asthma phenotypes may differ in clinical presentation, natural history, inflammatory mechanisms, response to treatment, and depend on age. ${ }^{6}$ The increasing awareness on heterogeneity of childhood asthma has also led to the recognition of underlying pathophysiological and/or molecular mechanisms (endotypes) and paved the way to the search for related specific indicators (biomarkers), which may guide diagnosis, phenotyping, management, and predict response to treatment. $^{7-9}$ The identification of biomarkers of childhood asthma is an active area of research that holds a potential great clinical utility and may represent a step forward toward tailored management and therapy: the so-called Precision Medicine, which is an emerging approach for disease treatment targeted to the needs of individual patients on the basis of genetic, biomarker, phenotypic, or psychosocial characteristics that distinguish a given patient from other patients with similar clinical presentations. ${ }^{10,11}$

\section{Phenotypes in Childhood Asthma}

Starting from the results of historical longitudinal cohort studies, epidemiologic and symptom-based criteria have been conventionally used to describe childhood asthma phenotypes. ${ }^{12-17}$ Atopy, reduced lung function, and viral and bacterial respiratory infections in wheezing infants have been identified as major risk factors for the persistence of asthma. Furthermore, a greater magnitude of atopy and lower lung function have been recognized as the main features of children with severe asthma in comparison with those with mild-to-moderate disease. ${ }^{4-6}$ However, tracking the course of the disease within longitudinal studies also revealed a limited practical utility of these disease variants, because of their complex heterogeneity, the possibility of overlapping features, and their instability over time. ${ }^{18}$

${ }^{1}$ Pediatric Clinic, Fondazione IRCCS San Matteo, Pavia, Italy.

${ }^{2}$ Pediatric Allergy, IRCCS Istituto Giannina Gaslini, Genoa, Italy.

${ }^{3}$ IRCCS Ospedale Policlinico San Martino, Genoa, Italy.

(C) Amelia Licari et al., 2018; Published by Mary Ann Liebert, Inc. This Open Access article is distributed under the terms of the Creative Commons Attribution Noncommercial License (http://creativecommons.org/licenses/by-nc/4.0/) which permits any noncommercial use, distribution, and reproduction in any medium, provided the original author(s) and the source are cited. 
Advanced statistical methods, such as cluster analysis and latent class analysis methodology, have recently renewed the interest in investigating and identifying new childhood asthma phenotypes. ${ }^{19-24}$ Phenotyping in children has been set on the basis of multiple variables: the presence or absence of atopy, the temporal patterns and the triggers of symptoms, the severity of the disease, the patterns of airway inflammation, and the response to medications, in particular for severe asthma. ${ }^{18,23-31}$ Results from cluster analyses studies on severe asthma highlighted that childhood-onset severe asthma is characterized by eosinophilic airway inflammation, male predominance, severe atopy with multiple sensitizations, airflow limitation, and early signs of airway remodeling, presenting itself differently from adult-onset phenotype and rapidly changing over time or in response to treatment. ${ }^{32-35}$ However, the large amount of data derived from these statistical categorizations is still more useful for researchers than clinicians, and has to be interpreted with caution, due to the variability of statistical methods used and to the lack of validation in several populations. ${ }^{36}$ Furthermore, the current identification of asthma phenotypes does not provide insight into the underlying pathogenic mechanisms and has limited clinical value in predicting outcomes and directing therapy.

Although it is already known that asthma has a strong genetic component, recent research studies indicate that variability in genotype contributes significantly to the heterogeneity of asthma phenotype and morbidity. ${ }^{37}$ Research on asthma susceptibility genes highlighted the role of ADAM33, a disintegrin and metalloproteinase domain 33 expressed in fibroblasts and smooth muscle cells, in regulating susceptibility of lung epithelium/fibroblasts to remodeling in response to allergic inflammation. ${ }^{38}$ Gene polymorphisms of $A D A M 33$ have been associated with an increased risk for childhood asthma, in particular in the Asian population, and with an excess decline in lung function in asthmatic subjects, representing potential markers of susceptibility and severity of disease. ${ }^{39}$ Genetic variants may also influence the response to therapy: one of the most investigated pharmacogenetic effects has been the effect of polymorphisms at the gene encoding the $\beta 2$-adrenergic receptor, $A D R B 2$, on the bronchodilator response to inhaled short- and long-acting $\beta$ agonists. Of particular interest is the Arg16Gly polymorphism of the ADRB2 gene, which is associated with enhanced downregulation and uncoupling of $\beta 2$-receptors and with differences in pulmonary function responsiveness to short-acting $\beta$ agonists in children. ${ }^{40}$ Furthermore, the use of long-acting $\beta$ agonists as add-on controller in asthmatic children carrying the Arg16Gly polymorphism has been associated with increased risk of asthma exacerbation. ${ }^{41,42}$ Thus, Arg16Gly polymorphism in the $\beta 2$ receptor might be considered a potential marker for optimizing therapy in pediatric asthma.

Clinical application of these genetic findings, as well as a better understanding of the modifying effects of environment on these genetic susceptibilities, may potentially lead to identification of new biologic pathways involved in the pathogenesis of the disease, the development of new therapeutic approaches, and the identification of at-risk individuals.

\section{Endotypes in Childhood Asthma}

In relation to asthma heterogeneity, the term "endotype" has recently been introduced to describe "a subtype of a condition defined by a unique or distinctive functional or pathophysiologic mechanism." 43,44 Therefore, the definition of inflammatory patterns of the disease is essential for endotyping asthma and better directing therapy. ${ }^{8}$

There are two major different endotypes defined for asthma: type 2 (T2)-high asthma and T2-low asthma, based on the type of underlying airway immune-mediated inflammation. ${ }^{44,45} \mathrm{~T} 2$ high asthma is typically characterized by eosinophilic inflammation, initiated by "alarmins," such as interleukin-25 (IL-25), IL-33, and thymic stromal lymphopoietin, all of which are secreted after a trigger in bronchial epithelium (ie, allergens, microbes, pollutants), and subsequently sustained by the release of signature cytokines IL-4, IL-5, and IL-13 from cells of both the innate and adaptive immune systems, including $\mathrm{T}$ helper 2 (Th2) cells, invariant T cells, natural killer (NK) cells, eosinophil/basophil progenitor cells, and type 2 innate lymphoid cells (ILC2s). ${ }^{45,46}$ Type 2 cytokines actively recruit eosinophils, mast cells, and basophils in the airways, and directly mediate immunoglobulin E (IgE) synthesis, then contributing to the hallmarks of asthma pathophysiology, such as mucus production, subepithelial fibrosis, bronchial remodeling, and AHR. ${ }^{47}$ T2-high asthma endotype typically displays a good response to corticosteroid therapy and, because probably there are more readily available biomarkers for its identification, has become the target of biological therapies (ie, anti-IgE, antiIL-5). ${ }^{35}$ Although less known and studied, T2-low asthma is driven by either a neutrophilic or, less commonly, paucigranulocytic inflammatory pattern, sustained by IL-8, IL-17A, IL-2,2, and other T cell-related cytokines, as well as epithelial cell-derived cytokines. ${ }^{48,49}$ T2-low asthma endotype is considered rare but mainly seen in patients with severe disease and shows a typical corticosteroid insensitivity, such as corticosteroid resistance. $^{50}$

In contrast with adults, in whom the cellular pattern of airway inflammation has been extensively studied with invasive and semi-invasive techniques [bronchial biopsies, bronchoalveolar lavage (BAL), and induced sputum], in children the majority of analyses were performed in the field of severe asthma. ${ }^{32,51-53}$ Three major endotypes of airway inflammation have been described in children with severe asthma: eosinophilic, neutrophilic, and paucigranulocytic inflammation. ${ }^{51-56}$

The eosinophilic endotype is the most common in childhood; it clinically matches with the early-onset severe asthma, characterized by uncontrolled symptoms, more atopy, impaired lung function, increased AHR, increased number of exacerbations, and steroid responsiveness compared with the other phenotypes. ${ }^{57}$ Unlike in adults, the levels of inflammatory cells in induced sputum have been reported to significantly vary over time in children with severe asthma and these variations were not related to changes in asthma therapy or asthma control. ${ }^{58}$ However, a persistent airway eosinophilia has been also described in a small subset of children with severe asthma, even after high-dose systemic corticosteroids. ${ }^{59}$ Bossley et al. recently characterized the pathology and mediators of inflammation and remodeling in a large cohort of 69 pediatric patients with severe therapy-resistant asthma (STRA), who underwent fiberoptic bronchoscopy, BAL, and endobronchial biopsy before a therapeutic trial with corticosteroids. Airway eosinophilia to varying degrees, without neutrophilia or increased mast cell counts, and initial features of remodeling were demonstrated in children with STRA; importantly, signature T2 cytokines were absent in 
the majority of children, with the exception of a small subgroup, confirming the disease heterogeneity even in the pediatric population. ${ }^{60}$ Furthermore, this eosinophilic airway inflammation was likely to persist despite systemic steroids in the majority of patients. ${ }^{61,62}$

In another study, Andersson et al. reported two subgroups within the pediatric STRA phenotype, which differ in the number of intraepithelial neutrophils detected in the bronchial biopsy; in the subgroup with increased intraepithelial airway neutrophilia, an exaggerated epithelial response to IL-17A was demonstrated, together with increased submucosal and epithelial expression of IL-17 receptor (IL-17R). ${ }^{63}$ In the same group, an interesting novel finding was that the number of intraepithelial airway neutrophils correlated with better lung function, better symptom control, and lower dose maintenance inhaled steroids. ${ }^{63}$

Recently, ILC2s have been identified in BAL, induced sputum, and peripheral blood from children with STRA ${ }^{64}$; these preliminary findings suggest a potential pivotal role of ILC2s in the molecular mechanisms of pediatric allergic severe asthma.

As in adults, the functional role of airway neutrophils in mediating pediatric asthma pathophysiology is still unclear. Neutrophilic infiltration may be a feature of airway inflammation at all ages and may be mostly triggered by exposure to viruses and bacterial endotoxins in the pediatric age, subsequently leading to asthma symptoms. ${ }^{65}$ Airway neutrophils have been assessed in a minority of children with severe asthma through induced sputum cytology. ${ }^{53}$ More recently, an increased number of intraepithelial neutrophils, together with an increased submucosal and epithelial expression of IL$17 \mathrm{R}$, have been determined in the lung biopsies of a subgroup of children with STRA; this finding was associated with better lung function, better symptom control, and lower dose maintenance inhaled corticosteroids $\left(\mathrm{ICS}^{63}\right)$; even if these results may question for the first time the association of neutrophils and poor response with corticosteroids, they require further validation. Finally, other studies reported the coexistence of neutrophils with eosinophils in the airway tissue, contributing to highlight the complexity of defining inflammatory endotypes in children with asthma. ${ }^{32,60}$

\section{Biomarkers in Childhood Asthma}

A biomarker is a quantifiable biological indicator that provides an objective measure of health status or disease. The ideal biomarker should be "measured in an analytical test system with established performance characteristics and should have a scientific body of evidence that elucidates the physiologic, pharmacologic, or clinical significance of the test results." 66 Furthermore, a valid biomarker should have practical availability and reliability. ${ }^{9}$

Biomarkers for asthma can be measured in different biological specimens, including sputum, BAL, exhaled breath condensate (EBC), bronchial biopsy, urine, and blood. ${ }^{67}$ Currently, BAL with bronchoscopy and bronchial biopsy are the gold standard to assess airway inflammation and remodeling in asthma; however, the invasiveness of these diagnostic methods limits their use in pediatric age in daily clinical practice. ${ }^{68,69}$ Sputum induction still has limited use outside the research setting, as it is considered semi-invasive as well as technically complex, especially in children younger than 8 years. ${ }^{70}$ Thus, the availability of noninvasive methods to study and monitor disease inflammation is of main relevance especially in childhood asthma.

Biomarkers for asthma have potential utility for distinguishing the inflammatory endotype (T2-high versus T2-low asthma), predict responsiveness to specific treatments (in particular, T2 cytokine-targeted therapy), monitor success of a selected treatment option, and assess the risk of disease progression. $^{47,71}$ Single and combination biomarkers are now being recommended for use in the assessment of patients with asthma, and in particular with severe asthma (Table 1).

\section{T2-high asthma biomarkers}

Most of the current established biomarkers available in clinical practice are related to T2-high inflammation. ${ }^{72,73}$

Table 1. Current Biomarkers in Childhood Asthma

\begin{tabular}{|c|c|c|c|}
\hline Biomarker & Sample type & Associated asthma endotype & Proposed use \\
\hline Eosinophil & Serum, sputum & T2-high & $\begin{array}{l}\text { Disease phenotyping } \\
\text { Severity of clinical symptoms } \\
\text { Monitoring of asthma control } \\
\text { Prediction of treatment response }\end{array}$ \\
\hline Neutrophil & Sputum & T2-high/T2-low & $\begin{array}{l}\text { Disease phenotyping } \\
\text { Under investigation }\end{array}$ \\
\hline $\operatorname{IgE}$ & Serum & T2-high & $\begin{array}{l}\text { Disease phenotyping } \\
\text { Severity of clinical symptoms }\end{array}$ \\
\hline Periostin & Serum & T2-high & $\begin{array}{l}\text { Disease phenotyping } \\
\text { Severity of clinical symptoms } \\
\text { Diagnosis } \\
\text { Prediction of treatment response }\end{array}$ \\
\hline FeNO & Exhaled air & T2-high & $\begin{array}{l}\text { Disease phenotyping } \\
\text { Severity of clinical symptoms } \\
\text { Monitoring of asthma control }\end{array}$ \\
\hline IL-17 & Serum & T2-low & Disease phenotyping \\
\hline EBC & Exhaled air & Not yet determined & Under investigation \\
\hline VOCs & Exhaled air & Not yet determined & Under investigation \\
\hline
\end{tabular}

EBC, exhaled breath condensate; FeNO, fractional exhaled nitric oxide; IgE, immunoglobulin E; IL, interleukin; T2, type 2; VOCs, volatile organic compounds. 
These include blood or sputum eosinophils, serum IgE, serum periostin, and fractional exhaled nitric oxide (FeNO). ${ }^{46}$

Eosinophils. Eosinophil is the central driver of T2 inflammation and represents the predominant inflammatory cell type in the airways of children with severe asthma, playing a major role in maintaining chronic inflammation. ${ }^{60,61,74-76}$ Although there is no standardized cutoff for eosinophilic inflammation, a blood eosinophil count of around 300 cells $/ \mu \mathrm{L}$ or a sputum eosinophil cell count above $2 \%-3 \%$ of the total cell count has been used as thresholds. ${ }^{77-79}$

Several studies demonstrated that blood eosinophil count well correlates with asthma severity and AHR in children. ${ }^{80-82}$ The presence of blood eosinophilia and high FeNO can be indicative of a good response to ICS, although less so for oral corticosteroid therapy. ${ }^{83}$ In the Individualized Therapy for Asthma in Toddlers (INFANT) trial, blood eosinophil counts of 300 cells/ $\mu \mathrm{L}$ or greater, together with aeroallergen sensitization, have been recently identified as predictors of best response to daily ICS in preschool asthmatic children requiring step 2 asthma treatment ${ }^{84}$; these results encourage further studies to better tailor treatments on preschool children with asthma, which present with numerous and variable phenotypic presentations that correspond to different outcomes and still suffer from significant therapeutic gaps. ${ }^{85}$ Elevated eosinophil numbers in peripheral blood ( $>400$ cells $/ \mu \mathrm{L})$ have been linked to a higher rate of severe asthma exacerbations. ${ }^{86}$ Recently, the use of blood eosinophil count has been assessed as a sensitive and practical predictive biomarker for biologic treatment in patients with severe asthma. A decrease in blood eosinophil count has been associated with a consistent pattern of improved clinical outcomes in patients with severe asthma receiving omalizumab $\left(\right.$ anti-IgE) ${ }^{87}$; with particular reference to the pediatric population, Busse et al. reported a high eosinophil count ( $>300$ cells/ $\mathrm{mL}$ ) to be a potential biomarker to predict successful omalizumab treatment effects. ${ }^{88}$ Furthermore, blood eosinophils, in combination with FeNO, and periostin were shown to identify patient subgroups that may achieve greater benefit from omalizumab therapy. ${ }^{89}$ Baseline blood eosinophil count threshold of 150 cells/ $\mu \mathrm{L}$ or greater and/or a historical blood eosinophil count threshold of 300 cells/ $\mu \mathrm{L}$ have been established as a biomarker to allow selection of adult patients with severe asthma who are most likely to benefit from mepolizumab (anti IL-5) therapy. ${ }^{90,91}$ However, this result cannot be translated in the pediatric population and clinical studies to assess the efficacy, pharmacokinetics, and pharmacodynamics of mepolizu$\mathrm{mab}$ in children with severe asthma are currently ongoing (NCT03292588 and NCT02377427). ${ }^{92}$

Peripheral blood eosinophilia is considered not as specific as sputum eosinophil, being potentially influenced by several confounding factors, such as allergen exposure, parasitic infections, and current corticosteroid therapy. However, the results of an external validation in two independent cohorts of patients with mild to moderate asthma showed that blood eosinophil had the highest accuracy in the identification of sputum eosinophilia, compared with FeNO and serum periostin. ${ }^{93}$ Nevertheless, peripheral blood eosinophilia does not always reflect pulmonary (airway or mucosal) eosinophilia in children with severe asthma. ${ }^{94}$

When feasible, sputum analysis can provide further information about the airway cellular composition and cytokines. Increased eosinophil number in sputum is a hallmark feature of atopy and asthma, ${ }^{95,96}$ is associated with AHR and airway obstruction, ${ }^{97,98}$ inversely correlates with forced expiratory volume in 1 second $\left(\mathrm{FEV}_{1}\right),{ }^{99}$ and acts as a predictor of severe asthma exacerbations, ${ }^{100-102}$ both in adults and children.

Sputum eosinophilia may also predict clinical response to corticosteroid therapy (both ICS and systemic treatment) and to biologic therapy. ${ }^{78,103,104}$ In a recent Cochrane revision, sputum analysis for the evaluation of percentage of sputum eosinophilia is considered beneficial in objectively monitoring asthma and guiding tailored therapeutic interventions to maintain control and reduce exacerbations in adults with asthma, while insufficient data are currently available for children. $58,105,106$

Total and allergen-specific IgE. Total IgE and especially allergen-specific IgE are the signatures of atopic status, associated with asthma. More than $80 \%$ of children with asthma show an allergic component; high levels of total IgE increase the risk of later asthma development in infants with viral-induced wheezing, ${ }^{107}$ while high levels of allergenspecific IgE (in particular for aeroallergens, such as house dust mites or furry animals) well correlate with asthma severity, mainly in children. ${ }^{108}$ Consequently, allergy screening should be routinely performed in patients with asthma, and total IgE should be checked in every child diagnosed with severe asthma to eventually address an add-on therapy with omalizumab. ${ }^{109,110}$

Periostin. Periostin is a secreted extracellular matrix protein that was originally identified in cells of the periosteum and involved in bone growth and repair. ${ }^{111}$ In addition, periostin is also an IL-4- and IL-13-inducible protein that is secreted by airway epithelial cells and lung fibroblasts and can be detected in peripheral blood, as well as in sputum and EBC. ${ }^{112}$ In this context, periostin plays a role as a mediator of several pathogenic processes in asthma, such as airway remodeling, subepithelial fibrosis, eosinophil recruitment, and regulation of mucus production from goblet cells. ${ }^{13-115}$ Several reports have suggested that serum periostin could be a useful biomarker of T2-high inflammation in adult asthmatic patients, since it has been demonstrated in overexpression in epithelial cells, upregulation by classic T2 cytokines such as IL-4 and IL-13, and ability to predict a clinical response to lebrikizumab (anti IL-13) and omalizumab treatment in severe asthmatics. ${ }^{88,116}$ However, periostin levels are known to be higher in children than in adults, most likely due to bone growth, and may overlap with local production within the airways, thus impairing the clinical utility in children; periostin levels may be also elevated in other concomitant diseases, such as rhinosinusitis with or without polyposis and atopic dermatitis. ${ }^{117}$ With these limitations, pediatric studies on periostin showed significantly higher values in children with asthma compared with healthy controls, a correlation between levels of serum periostin and induced-AHR, and a moderate relationship with blood eosinophilia and IgE in asthmatic children. ${ }^{118,119}$ It still remains unclear if periostin has a predictive value for identifying severe asthma in children.

Fractional exhaled nitric oxide. Nitric oxide (NO) is a signaling molecule produced by respiratory epithelial cells, is found in exhaled breath, functions as a vasodilator and bronchodilator in the lungs, and is synthesized from Larginine by inducible $\mathrm{NO}$ synthase enzymes in response to inflammatory cytokines. ${ }^{120}$ In particular, in asthmatic patients, allergen exposure results in IL-4 and IL-13 expression, which, acting through signal transducer and activator of transcription 6 , induces iNOS, resulting in significant 
increases in NO levels. ${ }^{121}$ FeNO measured in exhaled breath is one of most studied noninvasive biomarkers in recent years. Its measurement is simple, safe, and well tolerated, and it has been standardized in school-aged children. ${ }^{120,122}$ FeNO levels may be influenced by several factors, including smoking, diet, obesity, somatic variables, spirometry or exercise before testing, flow rate, nasal contamination, and ambient air. ${ }^{123}$

FeNO level may be useful as a predictive factor for newonset asthma in preschool children ${ }^{124}$ and has been shown to correlate with AHR, blood eosinophils, and serum $\operatorname{IgE}$ levels in children. ${ }^{125,126}$ In pediatric asthma, FeNO is now recognized as a surrogate marker of eosinophilic airway inflammation and it is used to identify children with allergic asthma who are likely to respond to ICS treatment. ${ }^{122}$ Multiple studies have demonstrated that an increased FeNO value at baseline or increasing FeNO values during ICS reduction accurately predict an asthma exacerbation. ${ }^{121}$ According to the cutoff values published in the American Thoracic Society (ATS) guidelines, an FeNO of $>35 \mathrm{ppb}$ suggests a likely response to ICS, while an FeNO of $<20 \mathrm{ppb}$ in children indicates a less likely responsiveness to ICS treatment. ${ }^{122}$ Although it has been suggested as a useful tool to guide treatment in childhood asthma, many studies show contradictory results in terms of its utility, mainly due to the differences in the design of the trials and in the selection of patients. ${ }^{127}$ The efficacy of tailoring asthma interventions based on FeNO has been evaluated in comparison with primary guideline management in asthmatic children in a recent Cochrane systematic review: the analysis of nine pediatric studies shows that the use of FeNO to guide asthma therapy significantly decreased the number of children who had one or more exacerbations over the study period but did not impact on the day-to-day clinical symptoms or ICS doses, so that its use cannot be recommended in routine clinical practice to tailor the dose of ICS for all children with asthma. ${ }^{128}$

Combination of biomarkers. Combination of these biomarkers has been evaluated to improve the identification of T2-high inflammation in asthma and to predict response to therapy. Prior studies in older children have shown the association of markers of allergic inflammation, such as $\mathrm{IgE}$ levels ( $>200 \mathrm{kU} / \mathrm{L}$ ), exhaled NO (values $>25 \mathrm{ppb}$ ), and eosinophilic cationic protein with response to ICS in older asthmatic children. ${ }^{129}$ In a cross-sectional study by Konradsen et al., FeNO, in combination with blood eosinophils, had a high predictive value for the identification of children with the highest asthma morbidity, while there was no association between asthma morbidity and serum levels of periostin. ${ }^{130}$ In another recent Swedish study, simultaneous increase of both FeNO and blood eosinophil count was correlated with a higher likelihood of AHR and uncontrolled asthma in a large cohort of young asthmatic patients. ${ }^{131}$ The combination of blood eosinophils and FeNO has been also investigated in the setting of pediatric severe asthma of Severe Asthma Research Program (SARP) study, showing increased values only in $30 \%-40 \%$ of subjects. ${ }^{24}$

Exhaled breath condensate. The EBC collection is a novel noninvasive technique that can be used to investigate several asthma biomarkers, including markers of oxidative stress (8isoprostane, hydrogen peroxide, aldehydes, and nitrite/nitrate), markers of inflammation (eicosanoids), $\mathrm{pH}$, temperature, microRNA profiles, and other cytokines. ${ }^{69}$ EBC analyzes microdroplets collected after cooling exhaled air and can be easily performed even in younger children with severe disease. ${ }^{69}$ Elevated levels of hydrogen peroxide, nitrites and nitrates, and leukotrienes B4 have been demonstrated in the EBC of children with asthma ${ }^{132,133}$ and higher levels of 8isoprostane and leukotrienes were both detected in children with severe asthma. ${ }^{134,135}$ EBC technology is actually dedicated to research studies in specialized centers and requires further standardization of the methodologies used for sample collection and analysis, before moving it to clinical practice.

Volatile organic compounds. Assessing volatile organic compounds (VOCs) in exhaled breath is another promising metabolomics approach for investigating airway inflammation in asthma. ${ }^{69}$ VOC analysis captures gaseous molecules (ie, hydrocarbons such as ethanol, acetone, isoprene, benzene, and many others) from exhaled air, originating from three main sources: the external environment, and endogenous metabolic processes both human and nonhuman (the microbiome). ${ }^{136}$ Considered a "molecular fingerprint" of breath, a combination of VOCs may represent a safe, noninvasive, and easy-to-sample tool for diagnosing and monitoring pediatric pulmonary diseases such as asthma. Previous studies performed in adults with asthma suggested good predictive accuracy of exhaled VOCs for asthma diagnosis and that several compounds, mainly alkanes, may be significantly associated with asthma inflammation. ${ }^{137,138}$

Although still limited to research settings, preliminary studies have proved the reliability of VOC assessment in distinguishing atopic and asthmatic from healthy children and in predicting exacerbations in asthmatic children. ${ }^{139,140}$ A recent revision of pediatric literature on VOC analysis in exhaled breath performed on wheezing or asthmatic children confirmed a moderate to good prediction accuracy (80\%$100 \%$, with a combination of VOCs) in pediatric asthma diagnosis. ${ }^{136}$ However, there are still various constraints associated with standardization of the different breath analysis techniques and further prospective cohort studies are needed to validate and introduce exhaled VOC profiling in a clinical scenario.

Other biomarkers. Novel biomarkers that may be associated with inflammation, but especially with remodeling processes, are emerging, since recent studies from pediatric severe asthma cohort studies showed that the pathophysiological abnormalities of asthma, inflammation, AHR, and remodeling may develop in parallel. ${ }^{141}$ However, a current limitation to the path of recognizing mechanisms of remodeling and related phenotypes is the relative difficulty in obtaining repeated invasive biopsies to assess longitudinal structural changes over time, especially in the pediatric population. Recently, the high mobility group box type 1 (HMGB1) protein has been proposed as a blood biomarker potentially able to elucidate one of the mechanisms of chronic airway dysfunction in asthma. ${ }^{142}$ HMGB1 is an inflammation marker of the alarmins family promoting immediate immune response to tissue damage, ${ }^{142}$ and is one of the most important damage-associated molecular pattern molecules, initiating and perpetuating immune responses in infectious and noninfectious inflammatory diseases. ${ }^{143}$ Its role is to act as a "danger signal" orchestrating homeostatic defensive responses in damaged tissues. ${ }^{142}$ Major structural features of HMGB1, a $30 \mathrm{kDa}$ nuclear and cytosolic ubiquitous protein, are its two DNA-binding domains, termed A and $\mathrm{B}$ box, and a negatively charged $\mathrm{C}$-terminal acidic 
region. HMGB1 contains two nuclear localization sequences, resides in the nucleus, and functions as a nonhistone chromatin-binding protein. ${ }^{144}$ Early work demonstrated that HMGB1 stabilizes chromatin structure and modulates gene transcription by bending the DNA helical structure. ${ }^{145}$ HMGB 1 can also be localized to the cytosolic compartment, implicating that it might also have important functions outside the nucleus. ${ }^{144}$ As a consequence of infection or apoptosis, HMGB1 is released in the extracellular compartment either by passive release from necrotic cells or active production by macrophages, dendritic cells, and NK cells. ${ }^{146}$ By binding to toll-like receptors (TLR) 2 and 4, and the receptor for advanced glycation end-products, ${ }^{147}$ HMGB1 upregulates the synthesis of inflammatory cytokines, elicits chemotaxis of inflammatory cells, and supports proliferation, chemotaxis, and synthesis of metalloproteinases by stromal fibroblasts, ${ }^{148}$ thereby contributing to the pathogenesis of both acute and chronic disorders. ${ }^{149}$ As for the potential pathogenic role of HMGB1 in the respiratory tract, a recent study has shown increased levels of the protein in children with stable, off-therapy, allergic asthma. ${ }^{150}$ Particularly, authors investigated the relationship between HMGB1 levels and lung function parameters, showing that sputum HMGB1 levels were higher in children with asthma than in healthy controls and, moreover, sputum HMGB1 levels also positively related to the serum total IgE levels in children with asthma. Finally, an inverse and strict correlation between sputum HMGB1 levels and pulmonary function indices was also observed in children with mild, moderate, and severe asthma. ${ }^{150}$

Existing data on further possible biomarkers of Th2mediated asthma need to be validated and their usefulness for clinical practice remains to be elucidated, in particular in the pediatric population.

\section{T2-low asthma biomarkers}

To date, biomarkers of T2-low asthma have not yet been established, at least in clinical practice. ${ }^{35}$ Unlike the eo- sinophilic counterpart, sputum neutrophils do not represent an established marker to define the T2-low asthma endotype, widely varying the different cutoff values used in the literature from as low as $40 \%$ to as high as $\geq 76 \%$. Moreover, blood neutrophils have limited accuracy and ability to predict sputum neutrophils across the spectrum of asthma severity. ${ }^{151}$ Serum progranulin, an epithelial-derived protein known to inhibit neutrophil degranulation, has been recently proposed as novel biomarker of neutrophilic inflammation in severe asthma patients with airflow limitation, ${ }^{152}$ but the exact mechanism of its anti-inflammatory action still remains unclear.

IL-17 has been found to play an important role in the pathogenesis of T2-low asthma, both in adults and children. ${ }^{50,62}$ It has been reported that IL-17 and its related cytokines are highly upregulated in bronchial and nasal mucosa of adult subjects with neutrophilic asthma prone to exacerbations. ${ }^{153}$ High levels of serum IL-17 have been also detected in children with asthma and, together with serum IgE and blood eosinophils, they could have a predictive value in diagnosing childhood asthma. ${ }^{154}$ Furthermore, both serum IL-17 and IL-17 ${ }^{+} \mathrm{T}$ cells have been associated with asthma severity in children. ${ }^{155,156}$

Among the many biomarkers investigated in the airways and blood of T2-low asthmatics, some of them are giving promising results for their future use in clinical practice. Human tumor necrosis factor-like weak inducer of apoptosis (TWEAK) is a protein expressed in various cell types, including inflammatory cells, such as monocytes, macrophages, dendritic cells, T cells, and NK cells; acting through its highly inducible receptor, named fibroblast growth factor-inducible 14 (Fn14), TWEAK may contribute to the development of airway inflammation and, in particular, potentially stimulate human bronchial epithelial cells to produce proinflammatory IL- 8 and granulocyte-macrophage colony-stimulating factor. ${ }^{157} \mathrm{Kim}$ et al. evaluated the airway TWEAK levels in a large population of 230 children with noneosinophilic asthma: sputum TWEAK levels were significantly elevated in children with asthma and higher in

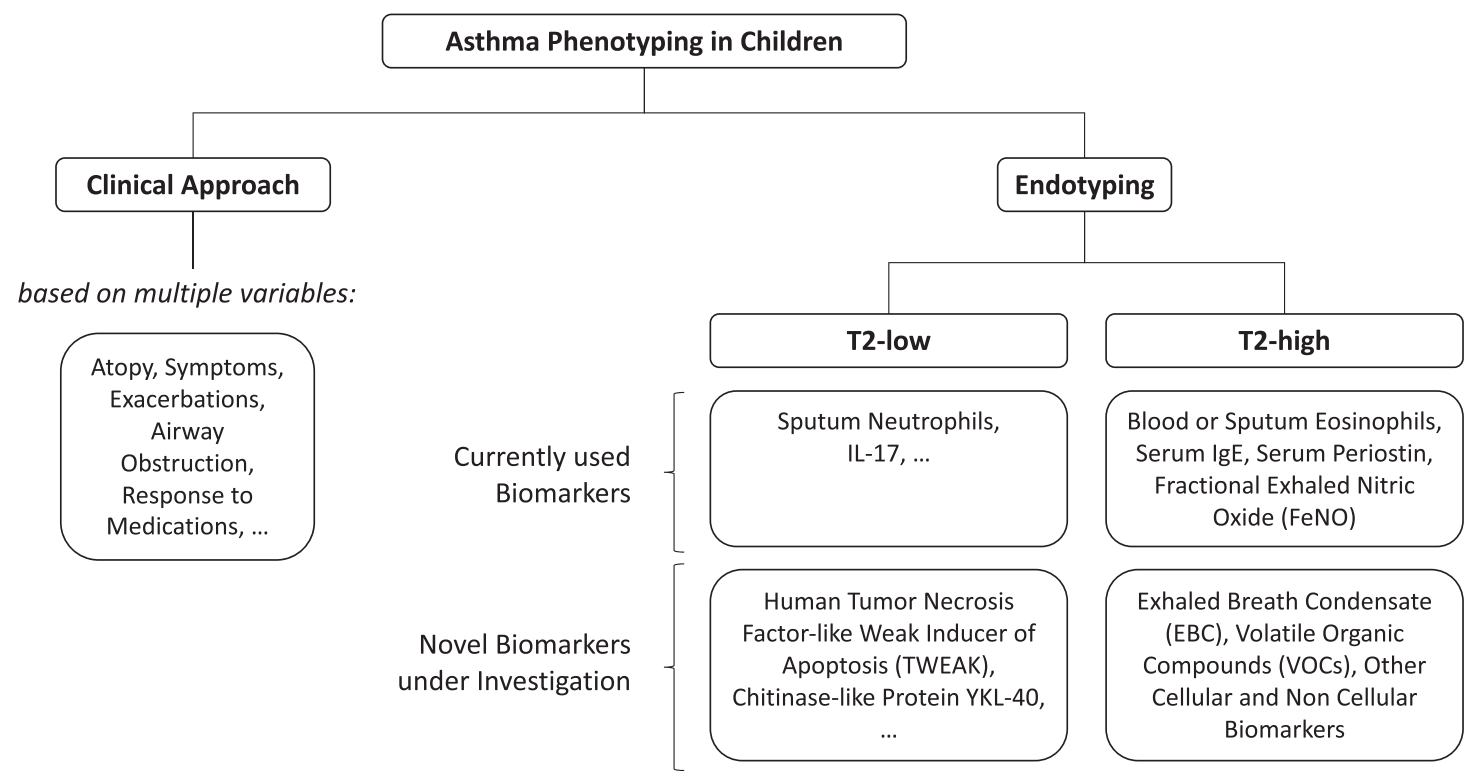

FIG. 1. Novel approach to phenotype and endotype childhood asthma. 
children with greater asthma severity and poorer control status; moreover, the authors found a negative correlation between sputum TWEAK levels and the spirometric parameters of bronchial obstruction, supporting the possible association of TWEAK with airway obstruction and remodeling. ${ }^{158}$ Thus, the TWEAK/Fn14 axis may also represent a future therapeutic target for limiting airway remodeling in asthma. YKL-40 is a chitinase-like protein that has a role in the inflammation and tissue remodeling in several human diseases. In adults, YKL-40 levels are increased in the blood and lungs of patients with asthma and correlate with lung function deficits, disease severity, and persistence. $^{159}$ Besides, circulating levels of YKL-40 are also elevated in children with persistent and severe asthma. ${ }^{160-162}$ Although YKL-40 represents a feasible biomarker for T2-low asthma, the exact mechanisms linking YKL-40 with asthma remain to be determined.

\section{Conclusions}

Childhood asthma represents a heterogeneous challenging disease, in particular in its severe forms. Clinical and morphologic characteristics of asthma phenotypes, as well as unique responses to different treatments, do not necessarily provide insights into the underlying pathophysiologic processes of airway inflammation. A careful assessment of inflammatory endotypes should be considered a central component of the workup and management of severe asthma in children. A limited number of biomarkers are currently available in clinical practice in the pediatric population, including blood and sputum eosinophils, serum IgE, periostin, and FeNO, mostly reflecting different molecular components of type 2-high airway inflammation (Fig. 1). Individually or in combination, they may help to improve diagnosis and predict severity of the disease and response to both conventional and novel biological targeted therapies. The type-2 low inflammatory endotype is still poorly characterized in particular in the pediatric population.

Current research efforts are aimed to integrate clinical characteristics and available combination of biomarkers to characterize asthma endotypes. Further research in childhood asthma biomarkers is needed to improve endotyping asthma, predicting major clinical outcomes and ultimately leading to personalized therapies.

\section{Author Disclosure Statement}

No competing financial interests exist.

\section{References}

1. Global Initiative for Asthma. GINA guidelines. Global strategy for Asthma Management and Prevention. Available at: www.ginasthma.org (accessed March 1, 2018).

2. Anderson HR, Gupta R, Kapetanakis V, Asher MI, Clayton $\mathrm{T}$, Robertson $\mathrm{CF}$, et al. International correlations between indicators of prevalence, hospital admissions and mortality for asthma in children. Int $\mathrm{J}$ Epidemiol 2008; 37:573-582.

3. Chung KF, Wenzel SE, Brozek JL, Bush A, Castro M, Sterk PJ, et al. International ERS/ATS guidelines on definition, evaluation and treatment of severe asthma. Eur Respir J 2014; 43:343-373.

4. Cowan K, Guilbert TW. Pediatric asthma phenotypes. Curr Opin Pediatr 2012; 24:344-351.
5. Reddy MB, Covar RA. Asthma phenotypes in childhood. Curr Opin Allergy Clin Immunol 2016; 16:127-134.

6. Just J, Bourgoin-Heck M, Amat F. Clinical phenotypes in asthma during childhood. Clin Exp Allergy 2017; 47:848855.

7. Deliu M, Yavuz TS, Sperrin M, Belgrave D, Sahiner UM, Sackesen C, et al. Features of asthma which provide meaningful insights for understanding the disease heterogeneity. Clin Exp Allergy 2018; 48:39-47.

8. Muraro A, Lemanske RF Jr, Hellings PW, Akdis CA, Bieber T, Casale TB, et al. Precision medicine in patients with allergic diseases: airway diseases and atopic dermatitis-PRACTALL document of the European Academy of Allergy and Clinical Immunology and the American Academy of Allergy, Asthma \& Immunology. J Allergy Clin Immunol 2016; 137:1347-1358.

9. Ciprandi G, Tosca MA, Silvestri M, Ricciardolo FLM. Inflammatory biomarkers for asthma endotyping and consequent personalized therapy. Expert Rev Clin Immunol 2017; 13:715-721.

10. Sánchez-García S, Habernau Mena A, Quirce S. Biomarkers in inflammometry pediatric asthma: utility in daily clinical practice. Eur Clin Respir J 2017; 4:1356160.

11. Agustí A, Bafadhel M, Beasley R, Bel EH, Faner R, Gibson PG, et al. Precision medicine in airway diseases: moving to clinical practice. Eur Respir J 2017; 50: 1701655.

12. Martinez FD, Wright AL, Taussig LM, Holberg CJ, Halonen M, Morgan WJ. Asthma and wheezing in the first six years of life. The Group Health Medical Associates. N Engl J Med 1995; 332:133-138.

13. Stein RT, Martinez FD. Asthma phenotypes in childhood: lessons from an epidemiological approach. Paediatr Respir Rev 2004; 5:155-161.

14. Rusconi F, Galassi C, Corbo GM, Forastiere F, Biggeri A, Ciccone $\mathrm{G}$, et al. Risk factors for early, persistent, and late-onset wheezing in young children. SIDRIA Collaborative Group. Am J Respir Crit Care Med 1999; 160: 1617-1622.

15. Henderson J, Granell R, Heron J, Sherriff A, Simpson A, Woodcock A, et al. Associations of wheezing phenotypes in the first 6 years of life with atopy, lung function and airway responsiveness in mid-childhood. Thorax 2008; 63:974-980.

16. Matricardi PM, Illi S, Grüber C, Keil T, Nickel R, Wahn $\mathrm{U}$, et al. Wheezing in childhood: incidence, longitudinal patterns and factors predicting persistence. Eur Respir $\mathbf{J}$ 2008; 32:585-592.

17. Savenije OE, Granell R, Caudri D, Koppelman GH, Smit HA, Wijga A, et al. Comparison of childhood wheezing phenotypes in 2 birth cohorts: ALSPAC and PIAMA. J Allergy Clin Immunol 2011; 127:1505-1512.e14.

18. Brand PL, Caudri D, Eber E, Gaillard EA, Garcia-Marcos L, Hedlin G, et al. Classification and pharmacological treatment of preschool wheezing: changes since 2008. Eur Respir J 2014; 43:1172-1177.

19. Guilbert TW, Mauger DT, Lemanske RF. Childhood asthma-predictive phenotype. J Allergy Clin Immunol Pract 2014; 2:664-670.

20. Garcia-Aymerich J, Benet M, Saeys Y, Pinart M, Basagaña $X$, Smit HA, et al. Phenotyping asthma, rhinitis and eczema in MeDALL population-based birth cohorts: an allergic comorbidity cluster. Allergy 2015; 70:973-984.

21. Howrylak J, Fuhlbrigge A, Strunk R, Zeiger RS, Weiss ST, Raby BA, et al. Classification of childhood asthma 
phenotypes and long-term clinical responses to inhaled anti-inflammatory medications. J Allergy Clin Immunol 2014; 133:1289-1300.

22. Schatz M, Hsu JW, Zeiger RS, Chen W, Dorenbaum A, Chipps BE, et al. Phenotypes determined by cluster analysis in severe or difficult-to-treat asthma. J Allergy Clin Immunol 2014; 133:1549-1556.

23. Depner M, Fuchs O, Genuneit J, Karvonen AM, Hyvärinen A, Kaulek V, et al. Clinical and epidemiologic phenotypes of childhood asthma. Am J Respir Crit Care Med 2014; 189:129-138.

24. Fitzpatrick AM, Teague WG, Meyers DA, Peters SP, Li $\mathrm{X}, \mathrm{Li} \mathrm{H}$, et al. Heterogeneity of severe asthma in childhood: confirmation by cluster analysis of children in the National Institutes of Health/National Heart, Lung, and Blood Institute Severe Asthma Research Program. J Allergy Clin Immunol 2011; 127:382-389.

25. Wenzel SE. Asthma phenotypes: the evolution from clinical to molecular approaches. Nat Med 2012; 18:716-725

26. Chen Q, Zhong X, Acosta L, Divjan A, Rundle A, Goldstein IF, et al. Allergic sensitization patterns identified through latent class analysis among children with and without asthma. Ann Allergy Asthma Immunol 2016; 116: 212-228.

27. Brand PLP, Baraldi E, Bisgaard H, Boner AL, CastroRodriguez JA, Custovic A, et al. Definition, assessment and treatment of wheezing disorders in preschool children: an evidence-based approach. Eur Respir J 2008; 32:1096-1110.

28. Spycher BD, Silverman M, Kuehni CE. Phenotypes of childhood asthma: are they real? Clin Exp Allergy 2010; 40:1130-1141.

29. Zoratti EM, Krouse RZ, Babineau DC, Pongracic JA, O'Connor GT, Wood RA, et al. Asthma phenotypes in inner-city children. J Allergy Clin Immunol 2016; 138: 1016-1029.

30. Sorkness RL, Zoratti EM, Kattan M, Gergen PJ, Evans MD, Visness CM, et al. Obstruction phenotype as a predictor of asthma severity and instability in children. $\mathrm{J}$ Allergy Clin Immunol 2017; [Epub ahead of print]; DOI: 10.1016/j.jaci.2017.09.047.

31. Chung KF. Targeting the interleukin pathway in the treatment of asthma. Lancet 2015; 386:1086-1096.

32. Fitzpatrick AM, Higgins M, Holguin F, Brown LA, Teague WG; National Institutes of Health/National Heart, Lung, and Blood Institute's Severe Asthma Research Program. The molecular phenotype of severe asthma in children. J Allergy Clin Immunol 2010; 125:851-857.

33. Fainardi V, Saglani S. The need to differentiate between adults and children when treating severe asthma. Expert Rev Respir Med 2015; 9:419-428.

34. Teague WG, Phillips BR, Fahy JV, Wenzel SE, Fitzpatrick AM, Moore WC, et al. Baseline Features of the Severe Asthma Research Program (SARP III) Cohort: differences with Age. J Allergy Clin Immunol Pract 2018; 6:545-554.e4.

35. Licari A, Castagnoli R, Brambilla I, Marseglia A, Tosca MA, Marseglia GL, et al. New approaches for identifying and testing potential new anti-asthma agents. Expert Opin Drug Discov 2018; 13:51-63.

36. Fuchs O, Bahmer T, Rabe KF, von Mutius E. Asthma transition from childhood into adulthood. Lancet Respir Med 2017; 5:224-234.

37. Mathias RA. Introduction to genetics and genomics in asthma: genetics of asthma. Adv Exp Med Biol 2014; 795: $125-155$.
38. Holgate ST. ADAM metallopeptidase domain 33 (ADAM33): identification and role in airways disease. Drug News Perspect 2010; 23:381-387.

39. Tripathi P, Awasthi S, Gao P. ADAM metallopeptidase domain 33 (ADAM33): a promising target for asthma. Mediators Inflamm 2014; 2014:572025.

40. Finkelstein Y, Bournissen FG, Hutson JR, Shannon M. Polymorphism of the ADRB2 gene and response to inhaled beta-agonists in children with asthma: a metaanalysis. J Asthma 2009; 46:900-905.

41. Lipworth BJ, Basu K, Donald HP, Tavendale R, Macgregor DF, Ogston SA, et al. Tailored second-line therapy in asthmatic children with the $\operatorname{Arg}(16)$ genotype. Clin Sci (Lond) 2013; 124:521-528.

42. Turner S, Francis B, Vijverberg S, Pino-Yanes M, Maitland-van der Zee AH, Basu K, et al. Childhood asthma exacerbations and the Arg16 $\beta 2$-receptor polymorphism: a meta-analysis stratified by treatment. J Allergy Clin Immunol 2016; 138:107-113.e5.

43. Lötvall J, Akdis CA, Bacharier LB, Bjermer L, Casale TB, Custovic A, et al. Asthma endotypes: a new approach to classification of disease entities within the asthma syndrome. J Allergy Clin Immunol 2011; 127:355-360.

44. Wenzel S. Severe asthma: from characteristics to phenotypes to endotypes. Clin Exp Allergy 2012; 42:650-658.

45. Woodruff PG, Modrek B, Choy DF, Jia G, Abbas AR, Ellwanger A, et al. T-helper type 2-driven inflammation defines major subphenotypes of asthma. Am J Respir Crit Care Med 2009; 180:388-395.

46. Robinson D, Humbert M, Buhl R, Cruz AA, Inoue H, Korom $\mathrm{S}$, et al. Revisiting Type 2-high and Type 2-low airway inflammation in asthma: current knowledge and therapeutic implications. Clin Exp Allergy 2017; 47:161-175.

47. Cosmi L, Liotta F, Maggi L, Annunziato F. Role of type 2 innate lymphoid cells in allergic diseases. Curr Allergy Asthma Rep 2017; 17:66.

48. Fahy JV. Type 2 inflammation in asthma-present in most, absent in many. Nat Rev Immunol 2015;15:57-65.

49. Hirose K, Iwata A, Tamachi T, Nakajima H. Allergic airway inflammation: key players beyond the Th2 cell pathway. Immunol Rev 2017; 278:145-161.

50. Samitas K, Zervas E, Gaga M. T2-low asthma: current approach to diagnosis and therapy. Curr Opin Pulm Med 2017; 23:48-55.

51. Mukherjee M, Svenningsen S, Nair P. Glucocortiosteroid subsensitivity and asthma severity. Curr Opin Pulm Med 2017; 23:78-88.

52. de Blic J, Tillie-Leblond I, Tonnel AB, Jaubert F, Scheinmann P, Gosset P. Difficult asthma in children: an analysis of airway inflammation. J Allergy Clin Immunol 2004; 113:94-100.

53. Lex C, Payne DNR, Zacharasiewicz A, Li AM, Wilson NM, Hansel TT, et al. Sputum induction in children with difficult asthma: safety, feasibility, and inflammatory cell pattern. Pediatr Pulmonol 2005; 39:318-324.

54. Hauk P, Krawiec M, Murphy J, Boguniewicz J, Schiltz A, Goleva E, et al. Neutrophilic airway inflammation and association with bacterial lipopolysaccharide in children with asthma and wheezing. Pediatr Pulmonol 2008; 43: 916-923.

55. Wenzel SE, Schwartz LB, Langmack EL, Halliday JL, Trudeau JB, Gibbs RL, et al. Evidence that severe asthma can be divided pathologically into two inflammatory subtypes with distinct physiologic and clinical characteristics. Am J Respir Crit Care Med 1999; 160:1001-1008. 
56. Gibson PG, Henry RL, Thomas P. Noninvasive assessment of airway inflammation in children: induced sputum, exhaled nitric oxide, and breath condensate. Eur Respir J 2000; 16:1008-1015.

57. Gibson PG, Simpson JL, Hankin R, Powell H, Henry RL. Relationship between induced sputum eosinophils and the clinical pattern of childhood asthma. Thorax 2003; 58: 116-121.

58. Guilbert TW, Bacharier LB, Fitzpatrick AM. Severe asthma in children. J Allergy Clin Immunol Pract 2014; 2: 489-500.

59. Fleming L, Tsartsali L, Wilson N, Regamey N, Bush A. Sputum inflammatory phenotypes are not stable in children with asthma. Thorax 2012; 67:675-681.

60. Payne DN, Adcock IM, Wilson NM, Oates T, Scallan M, Bush A. Relationship between exhaled nitric oxide and mucosal eosinophilic inflammation in children with difficult asthma, after treatment with oral prednisolone. Am J Respir Crit Care Med 2001; 164:1376-1381.

61. Bossley CJ, Fleming L, Gupta A, Regamey N, Frith J, Oates T, et al. Pediatric severe asthma is characterized by eosinophilia and remodeling without $\mathrm{T}(\mathrm{H}) 2$ cytokines. J Allergy Clin Immunol 2012; 129:974-982.e13.

62. Bossley CJ, Fleming L, Ullmann N, Gupta A, Adams A, Nagakumar P, et al. Assessment of corticosteroid response in pediatric patients with severe asthma by using a multidomain approach. J Allergy Clin Immunol 2016; 138: 413-420.e6.

63. Andersson CK, Adams A, Nagakumar P, Bossley C, Gupta $\mathrm{A}$, De Vries D, et al. Intraepithelial neutrophils in pediatric severe asthma are associated with better lung function. J Allergy Clin Immunol 2017; 139:1819-1829.e11.

64. Nagakumar P, Denney L, Fleming L, Bush A, Lloyd CM, Saglani S. Type 2 innate lymphoid cells in induced sputum from children with severe asthma. J Allergy Clin Immunol 2016; 137:624-626.e6.

65. Jochmann A, Artusio L, Robson K, Nagakumar P, Collins $\mathrm{N}$, Fleming L, et al. Infection and inflammation in induced sputum from preschool children with chronic airways diseases. Pediatr Pulmonol 2016; 51:778-786.

66. U.S. Food and Drug Administration. Guidance for industry: pharmacogenomic data submissions [Internet]. Silver Spring (MD): U.S. Food and Drug Administration; 2005. Available at: https://www.fda.gov/downloads/drugs/ guidancecomplianceregulatoryinformation/guidances/ucm 079849.pdf (accessed March 1, 2018).

67. Akdis CA, Agache I. Global Atlas of Asthma. Zurich, Switzerland: European Academy of Allergy and Clinical Immunology, 2013, pp. 34-35.

68. Vijverberg SJ, Hilvering B, Raaijmakers JA, Lammers JW, Maitland-van der Zee AH, Koenderman L. Clinical utility of asthma biomarkers: from bench to bedside. Biologics 2013; 7:199-210.

69. Moschino L, Zanconato S, Bozzetto S, Baraldi E, Carraro S. Childhood asthma biomarkers: present knowledge and future steps. Paediatr Respir Rev 2015; 16:205-212.

70. Kim CK, Koh YY, Callaway Z. The validity of induced sputum and bronchoalveolar lavage in childhood asthma. $\mathrm{J}$ Asthma 2009; 46:105-112.

71. Zissler UM, Esser-von Bieren J, Jakwerth CA, Chaker AM, Schmidt-Weber CB. Current and future biomarkers in allergic asthma. Allergy 2016; 71:475-494.

72. Agache I, Rogozea L. Asthma biomarkers: do they bring precision medicine closer to the clinic? Allergy Asthma Immunol Res 2017; 9:466-476.
73. Fitzpatrick AM, Moore WC. Severe asthma phenotypeshow should they guide evaluation and treatment? J Allergy Clin Immunol Pract 2017; 5:901-908.

74. Wadsworth S, Sin D, Dorscheid D. Clinical update on the use of biomarkers of airway inflammation in the management of asthma. J Asthma Allergy 2011; 4:77-86.

75. Prussin C, Metcalfe DD. 4. IgE, mast cells, basophils, and eosinophils. J Allergy Clin Immunol 2003; 111:S486-S494.

76. Saglani S, Lloyd CM. Eosinophils in the pathogenesis of paediatric severe asthma. Curr Opin Allergy Clin Immunol 2014; 14:143-148.

77. Nair P. What is an "eosinophilic phenotype" of asthma? J Allergy Clin Immunol 2013; 132:81-83.

78. Pavord ID, Korn S, Howarth P, Bleecker ER, Buhl R, Keene ON, et al. Mepolizumab for severe eosinophilic asthma (DREAM): a multicentre, double-blind, placebocontrolled trial. Lancet 2012; 380:651-659.

79. Schleich FN, Manise M, Sele J, Henket M, Seidel L, Louis R. Distribution of sputum cellular phenotype in a large asthma cohort: predicting factors for eosinophilic vs neutrophilic inflammation. BMC Pulm Med 2013; 13:11.

80. Brusselle GG, Maes T, Bracke KR. Eosinophils in the spotlight: eosinophilic airway inflammation in nonallergic asthma. Nat Med 2013; 19:977-979.

81. Casciano J, Krishnan JA, Small MB, Buck PO, Gopalan $\mathrm{G}$, Li C, et al. Value of peripheral blood eosinophil markers to predict severity of asthma. BMC Pulm Med 2016; 16:109.

82. Akar HH, Tahan F, Gungor HE. The association of forced expiratory volume in one second and forced expiratory flow at $50 \%$ of the vital capacity, peak expiratory flow parameters, and blood eosinophil counts in exerciseinduced bronchospasm in children with mild asthma. Asia Pac Allergy 2015; 5:98-102.

83. Cowan DC, Taylor DR, Peterson LE, Cowan JO, Palmay $\mathrm{R}$, Williamson A, et al. Biomarker-based asthma phenotypes of corticosteroid response. J Allergy Clin Immunol 2015; 135:877-883.e1.

84. Fitzpatrick AM, Jackson DJ, Mauger DT, Boehmer SJ, Phipatanakul W, Sheehan WJ, et al. Individualized therapy for persistent asthma in young children. J Allergy Clin Immunol 2016; 138:1608-1618.e12.

85. Raissy H, Blake K. Personalized medicine in preschool children with asthma. Pediatr Allergy Immunol Pulmonol 2017; 30:260-262.

86. Price D, Wilson AM, Chisholm A, Rigazio A, Burden A, Thomas M, et al. Predicting frequent asthma exacerbations using blood eosinophil count and other patient data routinely available in clinical practice. J Asthma Allergy 2016; 9:1-12.

87. Massanari M, Holgate ST, Busse WW, Jimenez P, Kianifard F, Zeldin R. Effect of omalizumab on peripheral blood eosinophilia in allergic asthma. Respir Med 2010; 104:188-196.

88. Busse W, Spector S, Rosén K, Wang Y, Alpan O. High eosinophil count: a potential biomarker for assessing successful omalizumab treatment effects. J Allergy Clin Immunol 2013; 132:485-486.e11.

89. Hanania NA, Wenzel S, Rosén K, Hsieh HJ, Mosesova S, Choy DF, et al. Exploring the effects of omalizumab in allergic asthma: an analysis of biomarkers in the EXTRA study. Am J Respir Crit Care Med 2013; 187:804-811.

90. Ortega HG, Yancey SW, Mayer B, Gunsoy NB, Keene ON, Bleecker ER, et al. Severe eosinophilic asthma treated with mepolizumab stratified by baseline eosinophil 
thresholds: a secondary analysis of the DREAM and MENSA studies. Lancet Respir Med 2016; 4:549-556.

91. Yancey SW, Keene ON, Albers FC, Ortega H, Bates S, Bleecker ER, et al. Biomarkers for severe eosinophilic asthma. J Allergy Clin Immunol 2017; 140:1509-1518.

92. Trial of Mepolizumab adjunctive therapy for the prevention of asthma exacerbations in urban children (MUPPITS-2). ClinicalTrials.gov Identifier: NCT03292588. Available at: https:/clinicaltrials.gov/ct2/show/NCT03292588?term= mepolizumab\&cond=Asthma+in+Children\&rank=2 (accessed March 1, 2018).

93. Wagener AH, de Nijs SB, Lutter R, Sousa AR, Weersink EJ, Bel EH, et al. External validation of blood eosinophils, $\mathrm{FE}(\mathrm{NO})$ and serum periostin as surrogates for sputum eosinophils in asthma. Thorax 2015; 70:115-120.

94. Ullmann N, Bossley CJ, Fleming L, Silvestri M, Bush A, Saglani S. Blood eosinophil counts rarely reflect airway eosinophilia in children with severe asthma. Allergy 2013; 68:402-406.

95. Belda J, Leigh R, Parameswaran K, O’Byrne PM, Sears MR, Hargreave FE. Induced sputum cell counts in healthy adults. Am J Respir Crit Care Med 2000; 161:475-478.

96. Vizmanos-Lamotte G, Moreno-Galdó A, Muñoz X, Gómez-Ollés S, Gartner S, Cruz MJ. Induced sputum cell count and cytokine profile in atopic and non-atopic children with asthma. Pediatr Pulmonol 2013; 48:1062-1069.

97. Toyran M, Bakirtas A, Dogruman-Al F, Turktas I. Airway inflammation and bronchial hyperreactivity in steroid naive children with intermittent and mild persistent asthma. Pediatr Pulmonol 2014; 49:140-147.

98. in't Veen JC, Smits HH, Hiemstra PS, Zwinderman AE, Sterk PJ, Bel EH. Lung function and sputum characteristics of patients with severe asthma during an induced exacerbation by double-blind steroid withdrawal. Am J Respir Crit Care Med 1999; 160:93-99.

99. Woodruff PG, Khashayar R, Lazarus SC, Janson S, Avila $\mathrm{P}$, Boushey HA, et al. Relationship between airway inflammation, hyperresponsiveness, and obstruction in asthma. J Allergy Clin Immunol 2001; 108:753-758.

100. Hastie AT, Moore WC, Meyers DA, Vestal PL, Li H, Peters $\mathrm{SP}$, et al. Analyses of asthma severity phenotypes and inflammatory proteins in subjects stratified by sputum granulocytes. J Allergy Clin Immunol 2010; 125:1028-1036.e13

101. Jatakanon A, Lim S, Barnes PJ. Changes in sputum eosinophils predict loss of asthma control. Am J Respir Crit Care Med 2000; 161:64-72.

102. Bjerregaard A, Laing IA, Backer V, Sverrild A, Khoo SK, Chidlow G, et al. High fractional exhaled nitric oxide and sputum eosinophils are associated with an increased risk of future virus-induced exacerbations: a prospective cohort study. Clin Exp Allergy 2017; 47:1007-1013.

103. van Rensen EL, Straathof KC, Veselic-Charvat MA, Zwinderman AH, Bel EH, Sterk PJ. Effect of inhaled steroids on airway hyperresponsiveness, sputum eosinophils, and exhaled nitric oxide levels in patients with asthma. Thorax 1999; 54:403-408.

104. Pizzichini MM, Pizzichini E, Clelland L, Efthimiadis A, Mahony J, Dolovich J, et al. Sputum in severe exacerbations of asthma: kinetics of inflammatory indices after prednisone treatment. Am J Respir Crit Care Med 1997; 155:1501-1508.

105. Petsky HL, Li A, Chang AB. Tailored interventions based on sputum eosinophils versus clinical symptoms for asthma in children and adults. Cochrane Database Syst Rev 2017; 8:CD005603.
106. Fleming L, Wilson N, Regamey N, Bush A. Use of sputum eosinophil counts to guide management in children with severe asthma. Thorax 2012; 67:193-198.

107. Lemanske RF Jr. The childhood origins of asthma (COAST) study. Pediatr Allergy Immunol 2002; 13:38-43.

108. Szefler SJ, Wenzel S, Brown R, Erzurum SC, Fahy JV, Hamilton RG, et al. Asthma outcomes: biomarkers. J Allergy Clin Immunol 2012; 1129:S9-S23.

109. Ciprandi G, Marseglia GL, Castagnoli R, Valsecchi C, Tagliacarne C, Caimmi S, et al. From IgE to clinical trials of allergic rhinitis. Expert Rev Clin Immunol 2015; 11: 1321-1333.

110. Licari A, Marseglia G, Castagnoli R, Marseglia A, Ciprandi $\mathrm{G}$. The discovery and development of omalizumab for the treatment of asthma. Expert Opin Drug Discov 2015; 10:1033-1042.

111. Chapurlat RD, Confavreux CB. Novel biological markers of bone: from bone metabolism to bone physiology. Rheumatology (Oxford) 2016; 55:1714-1725.

112. Bobolea I, Barranco P, Del Pozo V, Romero D, Sanz V, López-Carrasco V, et al. Sputum periostin in patients with different severe asthma phenotypes. Allergy 2015; 70: 540-546.

113. Sidhu SS, Yuan S, Innes AL, Kerr S, Woodruff PG, Hou $\mathrm{L}$, et al. Roles of epithelial cell-derived periostin in TGFbeta activation, collagen production, and collagen gel elasticity in asthma. Proc Natl Acad Sci U S A 2010; 107: 14170-14175.

114. Jia G, Erickson RW, Choy DF, Mosesova S, Wu LC, Solberg OD, et al. Periostin is a systemic biomarker of eosinophilic airway inflammation in asthmatic patients. $\mathbf{J}$ Allergy Clin Immunol 2012; 130:647-654.e10.

115. James A, Hedlin G. Biomarkers for the phenotyping and monitoring of asthma in children. Curr Treat Options Allergy 2016; 3:439-452.

116. Maxfield AZ, Landegger LD, Brook CD, Lehmann AE, Campbell AP, Bergmark RW, et al. Periostin as a biomarker for nasal polyps in chronic rhinosinusitis. Otolaryngol Head Neck Surg 2018; 158:181-186.

117. Sung M, Lee KS, Ha EG, Lee SJ, Kim MA, Lee SW, et al. An association of periostin levels with the severity and chronicity of atopic dermatitis in children. Pediatr Allergy Immunol 2017; 28:543-550.

118. Song JS, You JS, Jeong SI, Yang S, Hwang IT, Im YG, et al. Serum periostin levels correlate with airway hyperresponsiveness to methacholine and mannitol in children with asthma. Allergy 2015; 70:674-681.

119. Inoue T, Akashi K, Watanabe M, Ikeda Y, Ashizuka S, Motoki T, et al. Periostin as a biomarker for the diagnosis of pediatric asthma. Pediatr Allergy Immunol 2016; 27:521-526.

120. Baraldi E, de Jongste JC; European Respiratory Society/ American Thoracic Society (ERS/ATS) Task Force. Measurement of exhaled nitric oxide in children, 2001. Eur Respir J 2002; 20:223-237.

121. Spahn JD, Malka J, Szefler SJ. Current application of exhaled nitric oxide in clinical practice. J Allergy Clin Immunol 2016; 138:1296-1298.

122. Dweik RA, Boggs PB, Erzurum SC, Irvin CG, Leigh MW, Lundberg JO, et al. An official ATS clinical practice guideline: interpretation of exhaled nitric oxide levels (FENO) for clinical applications. Am J Respir Crit Care Med 2011; 184:602-615.

123. Pijnenburg MW, De Jongste JC. Exhaled nitric oxide in childhood asthma: a review. Clin Exp Allergy 2008; 38: 246-259. 
124. Gabriele C, Jaddoe VW, van Mastrigt E, Arends LR, Hofman A, Moll HA, et al. Exhaled nitric oxide and the risk of wheezing in infancy: the Generation R Study. Eur Respir J 2012; 39:567-572.

125. Kotaniemi-Syrjänen A, Malmberg LP, Malmström K, Pelkonen AS, Mäkelä MJ. Factors associated with elevated exhaled nitric oxide fraction in infants with recurrent respiratory symptoms. Eur Respir J 2013; 41:189-194.

126. Fang LC, Shyur SD, Wang JY, Kao YH, Yang CH, Yu YT. Exhaled nitric oxide helps discriminating asthmatic children with and without positive specific IgE to aeroallergens. Asian Pac J Allergy Immunol 2017; [Epub ahead of print]; DOI: 10.12932/AP-270717-0126.

127. Gomersal T, Harnan S, Essat M, Tappenden P, Wong R, Lawson R, et al. A systematic review of fractional exhaled nitric oxide in the routine management of childhood asthma. Pediatr Pulmonol 2016; 51:316-328.

128. Petsky HL, Kew KM, Chang AB. Exhaled nitric oxide levels to guide treatment for children with asthma. Cochrane Database Syst Rev 2016;11:CD011439.

129. Szefler SJ, Phillips BR, Martinez FD, Chinchilli VM, Lemanske RF, Strunk RC, et al. Characterization of withinsubject responses to fluticasone and montelukast in childhood asthma. J Allergy Clin Immunol 2005; 115:233-242.

130. Konradsen JR, Skantz E, Nordlund B, Lidegran M, James A, Ono J, et al. Predicting asthma morbidity in children using proposed markers of Th2-type inflammation. Pediatr Allergy Immunol 2015; 26:772-779.

131. Malinovschi A, Janson C, Borres M, Alving K. Simultaneously increased fraction of exhaled nitric oxide levels and blood eosinophil counts relate to increased asthma morbidity. J Allergy Clin Immunol 2016; 138:13011308.e2.

132. Glowacka E, Jedynak-Wasowicz U, Sanak M, Lis G. Exhaled eicosanoid profiles in children with atopic asthma and healthy controls. Pediatr Pulmonol 2013; 48:324-335.

133. Formanek W, Inci D, Lauener RP, Wildhaber JH, Frey U, Hall GL. Elevated nitrite in breath condensates of children with respiratory disease. Eur Respir J 2002; 19:487-491.

134. Zanconato S, Carraro S, Corradi M, Alinovi R, Pasquale MF, Piacentini G, et al. Leukotrienes and 8-isoprostane in exhaled breath condensate of children with stable and unstable asthma. J Allergy Clin Immunol 2004; 113:257-263.

135. Samitas K, Chorianopoulos D, Vittorakis S, Zervas E, Economidou E, Papatheodorou G, et al. Exhaled cysteinyl-leukotrienes and 8-isoprostane in patients with asthma and their relation to clinical severity. Respir Med 2009; 103:750-756.

136. Neerincx AH, Vijverberg SJH, Bos LDJ, Brinkman P, van der Schee MP, de Vries R, et al. Breathomics from exhaled volatile organic compounds in pediatric asthma. Pediatr Pulmonol 2017; 52:1616-1627.

137. Rufo JC, Madureira J, Fernandes EO, Moreira A. Volatile organic compounds in asthma diagnosis: a systematic review and meta-analysis. Allergy 2016; 71:175-188.

138. de Vries R, Dagelet YWF, Spoor P, Snoey E, Jak PMC, Brinkman $\mathrm{P}$, et al. Clinical and inflammatory phenotyping by breathomics in chronic airway diseases irrespective of the diagnostic label. Eur Respir J 2018; 51:1701817.

139. Fens N, van der Schee MP, Brinkman P, Sterk PJ. Exhaled breath analysis by electronic nose in airways disease. Established issues and key questions. Clin Exp Allergy 2013; 43:705-715.

140. Robroeks CM, van Berkel JJ, Jöbsis Q, van Schooten FJ, Dallinga JW, Wouters EF, et al. Exhaled volatile organic compounds predict exacerbations of childhood asthma in a 1-year prospective study. Eur Respir J 2013; 42:98-106.

141. Wilson SJ, Rigden HM, Ward JA, Laviolette M, Jarjour NN, Djukanović R. The relationship between eosinophilia and airway remodelling in mild asthma. Clin Exp Allergy 2013; 43:1342-1350.

142. Harris HE, Raucci A. Alarmin(g) news about danger: workshop on innate danger signals and HMGB1. EMBO Rep 2006; 7:774-778.

143. Campana L, Bosurgi L, Bianchi ME, Manfredi AA, Rovere-Querini P. Requirement of HMGB1 for stromal cell-derived factor-1/CXCL12-dependent migration of macrophages and dendritic cells. J Leukoc Biol 2009; 86: 609-615.

144. Javaherian K, Sadeghi M, Liu LF. Nonhistone proteins HMG1 and HMG2 unwind DNA double helix. Nucleic Acids Res 1979; 6:3569-3580.

145. Bustin M, Neihart NK. Antibodies against chromosomal HMG proteins stain the cytoplasm of mammalian cells. Cell 1979; 16:181-189.

146. Gallucci S, Matzinger P. Danger signals: SOS to the immune system. Curr Opin Immunol 2001; 13:114-119.

147. Yu M, Wang H, Ding A, Golenbock DT, Latz E, Czura CJ, et al. HMGB1 signals through toll-like receptor (TLR) 4 and TLR2. Shock 2006; 26:174-179.

148. Ojo OO, Ryu MH, Jha A, Unruh H, Halayko AJ. Highmobility group box 1 promotes extracellular matrix synthesis and wound repair in human bronchial epithelial cells. Am J Physiol Lung Cell Mol Physiol 2015; 309: L1354-L1366.

149. Kang R, Chen R, Zhang Q, Hou W, Wu S, Cao L, et al. HMGB1 in health and disease. Mol Aspects Med 2014; 40:1-116.

150. Manti S, Leonardi S, Parisi GF, De Vivo D, Salpietro A, Spinuzza A, et al. High mobility group box 1: biomarker of inhaled corticosteroid treatment response in children with moderate-severe asthma. Allergy Asthma Proc 2017; 38:197-203.

151. Hastie AT, Moore WC, Li H, Rector BM, Ortega VE, Pascual RM, et al. Biomarker surrogates do not accurately predict sputum eosinophil and neutrophil percentages in asthmatic subjects. J Allergy Clin Immunol 2013; 132:7280.

152. Park SY, Hong GH, Park S, Shin B, Yoon SY, Kwon HS, et al. Serum progranulin as an indicator of neutrophilic airway inflammation and asthma severity. Ann Allergy Asthma Immunol 2016; 117:646-650.

153. Ricciardolo FLM, Sorbello V, Folino A, Gallo F, Massaglia GM, Favatà G, et al. Identification of IL-17F/ frequent exacerbator endotype in asthma. J Allergy Clin Immunol 2017; 140:395-406.

154. Mansour AI, Abd Almonaem ER, Behairy OG, Gouda TM. Predictive value of IL-35 and IL-17 in diagnosis of childhood asthma. Scand J Clin Lab Invest 2017; 77:373378.

155. Chien JW, Lin CY, Yang KD, Lin CH, Kao JK, Tsai YG. Increased IL-17A secreting CD4+ T cells, serum IL-17 levels and exhaled nitric oxide are correlated with childhood asthma severity. Clin Exp Allergy 2013; 43:10181026.

156. Wisniewski JA, Muehling LM, Eccles JD, Capaldo BJ, Agrawal R, Shirley DA, et al. TH1 signatures are present in the lower airways of children with severe asthma, regardless of allergic status. J Allergy Clin Immunol 2017; [Epub ahead of print]; DOI: 10.1016/j.jaci.2017.08.020. 
157. Zhu C, Zhang L, Liu Z, Li C, Bai Y. TWEAK/Fn14 interaction induces proliferation and migration in human airway smooth muscle cells via activating the NF- $\mathrm{KB}$ pathway. J Cell Biochem 2018;119:3528-3536.

158. Kim SY, Kim JD, Sol IS, Kim MJ, Kim MN, Hong JY, et al. Sputum TWEAK expression correlates with severity and degree of control in non-eosinophilic childhood asthma. Pediatr Allergy Immunol 2018;29:42-49.

159. Gomez JL, Yan X, Holm CT, Grant N, Liu Q, Cohn L, et al. Characterisation of asthma subgroups associated with circulating YKL-40 levels. Eur Respir J 2017; 50: 1700800.

160. Leonardi S, Filippelli M, Lanzafame A, Parisi G, Mistrello G, Musumeci M, et al. Serum YKL-40 in children with asthma. J Biol Regul Homeost Agents 2015; 29:114119.

161. Konradsen JR, James A, Nordlund B, Reinius LE, Söderhäll C, Melén E, et al. The chitinase-like protein YKL-
40: a possible biomarker of inflammation and airway remodeling in severe pediatric asthma. J Allergy Clin Immunol 2013; 132:328-335.e5.

162. Guerra S, Melén E, Sunyer J, Xu CJ, Lavi I, Benet M, et al. Genetic and epigenetic regulation of YKL-40 in childhood. J Allergy Clin Immunol 2018; 141:1105-1114.

Address correspondence to: Giorgio Ciprandi, $M D$ IRCCS Ospedale Policlinico San Martino Largo Rosanna Benzi, 10 Genoa 16132 Italy

E-mail: gio.cip@libero.it

Received for publication February 5, 2018; accepted after revision March 23, 2018. 